\title{
Long-Term Management for Ventilator-Assisted Children in Hong Kong: 2 Decades' Experience
}

\author{
Shuk-Kuen Chau MBBS MRCPCH, Ada Wing-Yan Yung MBBS MRCPCH MMedSc, and \\ So-Lun Lee MBBS MRCPCH MPH
}

\begin{abstract}
BACKGROUND: The population of children receiving long-term mechanical ventilation is growing worldwide, but only limited data exist in Asian regions. The objective of the study was to review the management of these children in Hong Kong over the past 2 decades. METHODS: This was a retrospective cohort study. Hospital records from subjects receiving mechanical ventilation for $>3$ months were retrieved. Demographic characteristics and medical information of subjects ( $\leq 21 \mathrm{y}$ old) under the care of the ventilator program at the Duchess of Kent Children's Hospital between 1997 and 2015 were reviewed. RESULTS: There were a total of 96 subjects, with male predominance $(75 \%)$. Twenty-five subjects $(26 \%)$ required invasive mechanical ventilation via tracheostomy, and the median age of starting ventilation was much lower than for subjects receiving noninvasive ventilation ( 1.6 vs 11.2 y, $P$.003). Underlying causes included neuromuscular diseases $(50 \%)$; abnormal ventilatory control related to neurological, metabolic, or genetic conditions (25\%); airway problems (18\%); and chronic lung diseases (6\%). Comorbidities were frequent, with significantly more subjects receiving invasive mechanical ventilation who required gastrostomy or nasogastric tube feeding and had intellectual impairment. Despite their medical complexities, most of our subjects $(\mathbf{8 7 . 5 \%})$ could be discharged and resided in the community. Social reasons were the obstacles for discharge in 12 subjects receiving invasive mechanical ventilation. Seventeen subjects who died were receiving noninvasive ventilation, and most had progressive neuromuscular diseases. Only $8 \%$ subjects could be weaned off of ventilator support. At the time of the report, about one third of the subjects have reached adult age. CONCLUSIONS: Our study showed a steady growth in the number of children receiving long-term mechanical ventilation, similar to that in western countries, yet these children have distinct demographic characteristics, underlying diseases, comorbidities, and outcomes. Home care is feasible in the majority of these children despite a lack of in-home nursing care provision. Prolonged survival of these subjects necessitates the enhancement of transitional care to adult service. Key words: Children; long term mechanical ventilation; tracheostomy; noninvasive ventilation; home care; respiratory insufficiency. [Respir Care 2017;62(1):54-64. (C) 2017 Daedalus Enterprises]
\end{abstract}

\section{Introduction}

The population of children receiving long-term mechanical ventilation is growing worldwide. This can be largely attributed to advances in neonatal and pediatric intensive care and an increase in survival of children who suffer

The authors are affiliated with the Department of Pediatrics and Adolescent Medicine, Duchess of Kent Children's Hospital, Sandy Bay Road, Hong Kong.

The authors have disclosed no conflicts of interest. from critical illnesses (eg, severe congenital airway problems, acquired lung or brain injuries, or deteriorating neurological or neuromuscular diseases). Moreover, advances in respiratory care of neuromuscular patients have im-

\footnotetext{
Correspondence: So-Lun Lee MBBS MRCPCH MPH, Department of Pediatrics and Adolescent Medicine, Duchess of Kent Children's Hospital, 12 Sandy Bay Road, Pokfulam, Hong Kong. E-mail: slleem@hku.hk.
}

DOI: $10.4187 /$ respcare.04989 


\section{Long-Term Management for Ventilator-Assisted Children}

proved the outcome of these patients and have encouraged their caregivers to change from a traditional non-interventional to a more aggressive, supportive view. ${ }^{1,2}$ In the past, most of these ventilator-assisted children would stay in the hospital indefinitely, but the unequivocal negative effects of prolonged hospitalization on children's physical and emotional development have driven medical teams to attempt early discharge of these children back to the community. ${ }^{3}$ The availability of portable home ventilators and different interfaces for delivering noninvasive ventilation render home care a feasible option even for very young children. ${ }^{4,5}$

The care for these children receiving long-term mechanical ventilation is challenging, and the health cost is tremendous. A few international guidelines on the home care of these children have been published.6,7 Regional and national surveys about long-term care programs for these children have been conducted in many western countries, including the United Kingdom, the United States, Canada, France, Italy, Chile, Australia, and New Zealand, ${ }^{8-21}$ but only a few were longitudinal studies. The culture, social environment, and health insurance systems are different among Asian and Western countries, so more studies in Asia are warranted. Only a very few surveys were available in Asian countries, including one from Japan that was reported 2 decades ago, ${ }^{22}$ one from Taiwan that mainly involved hospitalized subjects, ${ }^{23}$ and one from Korea that focused on children with neuromuscular diseases. ${ }^{24}$

In Hong Kong, $>90 \%$ of all in-patient hospital services are covered by the Hospital Authority, a public hospital system heavily funded by the government. Annual reports of the Hospital Authority revealed that ventilator-assisted children accounted for persistently high bed occupancy in pediatric ICUs. Our ventilator care program at the Duchess of Kent Children's Hospital, a rehabilitation hospital under the Hospital Authority, was started in 1997. Our ventilator care ward is one of the 2 centers in Hong Kong that are responsible for the management of children receiving longterm mechanical ventilation and covers the majority of in-patient service for these children. Our multi-disciplinary team consists of pediatricians with expertise in rehabilitation, respiratory medicine, developmental pediatrics, and neurology and allied health professionals, including physiotherapists, occupational therapists, speech therapists, medical social workers, clinical psychologists, and nursing colleagues. Under the program, patients will receive comprehensive management addressing their rehabilitation needs and regular review of their ventilatory requirements. Caregivers will be empowered to take care of these ventilator-assisted children, including care of tracheostomy, care of gastrostomy, delivery of feeding and medications via gastrostomy or nasogastric tubes, etc. They will also learn various airway clearance techniques, including percussion and drainage, suctioning of airway, assisted-coughing ma-

\section{QUICK LOOK}

\section{Current knowledge}

Advances in medical care and technology have significantly improved survival rates for critically ill children, with a substantial proportion requiring long-term mechanical ventilation. The care for these children is challenging, and the health cost is tremendous. Recent regional and national surveys have shown that many of these children can be cared for at home despite potential barriers. Only limited data exist in Asia region.

\section{What this paper contributes to our knowledge}

The population of children receiving long-term mechanical ventilation in Hong Kong is growing, similar to western countries. However, these children were shown to have distinct demographic characteristics, underlying diseases, co-morbidities, and outcomes as compared with those reported in the literature. This supports the importance of obtaining local information for this challenging medical condition to facilitate health-care planning.

neuvers such as abdominal thrust, and air stacking techniques using glossopharyngeal breathing or insufflation via a manual resuscitation bag. Whenever necessary, liaison will be made with the local government departments, including social welfare, education, housing, transportation, and fire service to facilitate their discharge from the hospital and re-integration into the community.

We reviewed our program over the past 2 decades and compared the results with other overseas studies. We examined the underlying diseases responsible for the need of mechanical ventilation, the mode of ventilation chosen over the years, and the longitudinal outcomes of these children. The aims were to gain a better understanding of the characteristics of this unique group of patients, to assess the feasibility of home care, and to identify the potential service gaps. We anticipated that the results would enhance health-care planning not just locally but also in Asia.

\section{Methods}

This was a retrospective cohort study. We included all subjects who started receiving mechanical ventilation when they were $\leq 21$ y old, from July 1, 1997, to December 31, 2015. The cut-off at 21 y of age for our ventilator care program is related to the eligibility for disabled children to continue with their secondary school curriculum in special schools until this age. We defined long-term mechanical ventilation as continuous daily use of invasive or nonin- 


\section{Long-Term Management for Ventilator-Assisted Children}

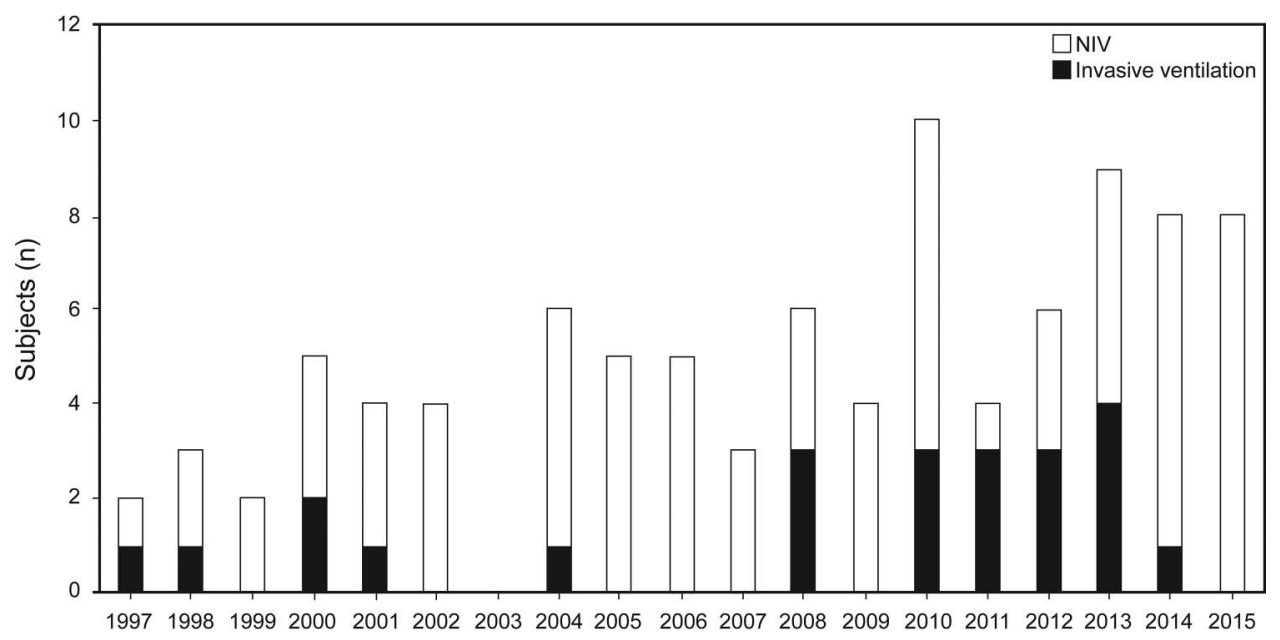

Fig. 1. Annual incidence of subjects initiated on long-term mechanical ventilation during the study period from 1997 to 2015. Note: Our ventilator care program did not receive new referrals in 2003 due to the severe acute respiratory syndrome epidemic.

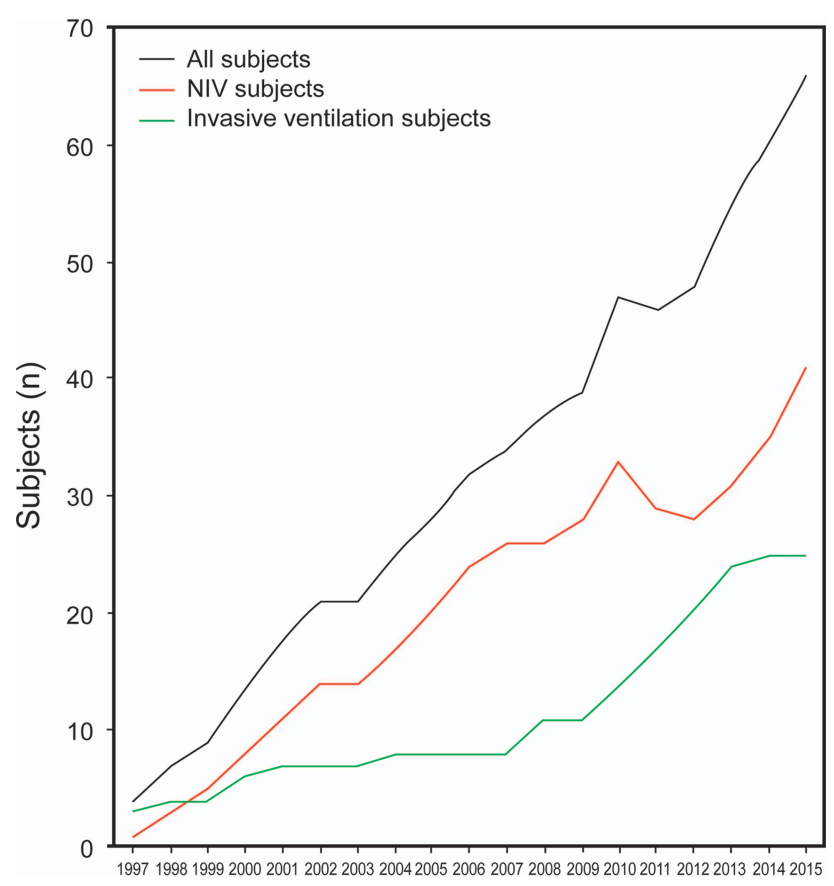

Fig. 2. Cumulative prevalence of subjects receiving long-term ventilation and under active follow-up during the study period from July 1997 to December 2015. Subjects who were lost to follow-up, died, or were weaned off of ventilation were considered inactive. NIV = noninvasive ventilation

vasive positive-pressure ventilation for $\geq 3$ months. Invasive mechanical ventilation refers to mechanical ventilation via tracheostomy. Noninvasive ventilation (NIV) refers to positive-pressure ventilation via an interface (eg, nasal mask, nasal prongs, mouthpiece, or oronasal mask). We excluded children with simple obstructive sleep apnea who required nocturnal CPAP because they generally did not require the multidisciplinary input from our ventilator care program.
Hospital records were retrieved, and subjects' information was extracted. This included basic demographic data like sex and age; indication for long-term mechanical ventilation; age at initiation of ventilation; type and mode of ventilation; duration of ventilation use each day (categorized as nocturnal use, extended daytime use, and wholeday use); presence of comorbidities, including limitation in mobility, gastrostomy or nasogastric tube feeding, and intellectual impairment; location of care, which would be either in the community or long-term in-patient care in our hospital; and outcome at the time of the report. Additional data collected for subjects receiving invasive mechanical ventilation included date of tracheostomy and length of stay in the acute referring hospital and our rehabilitation hospital.

Demographic data and medical information of the entire group or subgroups are presented as percentages, mean $\pm \mathrm{SD}$, or median (interquartile range [IQR]), as appropriate. Comparisons between groups were performed with an unpaired $t$ test for continuous parametric variables or Fisher exact test for categorical variables. A $P$ value of $<.05$ was considered as significant. All of the analysis was performed using statistical software SPSS 19.0 (SPSS, Chicago, Illinois). The study protocol was approved by the Hong Kong West Cluster/University of Hong Kong institutional review board (reference UW 15-363), who considered that informed consent was unnecessary because this was a retrospective study without subject identifiers.

\section{Results}

There have been a total of 96 subjects receiving longterm mechanical ventilation under our program from the time of its commencement in July 1997 to the time of the report in December 2015. Figures 1 and 2 show the annual 


\section{Long-Term Management for Ventilator-Assisted Children}

Table 1. Demographic Characteristics of 96 Subjects Under the Ventilator Care Program (July 1997 to December 2015)

\begin{tabular}{|c|c|c|c|}
\hline Characteristics & $\begin{array}{l}\text { Invasive Mechanical } \\
\text { Ventilation }(n=25)\end{array}$ & $\begin{array}{c}\text { Noninvasive } \\
\text { Ventilation }(n=71)\end{array}$ & $P$ \\
\hline Male sex, $n(\%)$ & $17(68 \%)$ & $55(77 \%)$ & .42 \\
\hline \multicolumn{4}{|l|}{ Age at initiation of ventilator support, $y$} \\
\hline Mean + S.D. & $5.2 \pm 6$ & $10.3 \pm 7.6$ & .003 \\
\hline Median (IQR) & $1.6(0.7-8.7)$ & $11.2(2.1-17.5)$ & \\
\hline \multirow[t]{2}{*}{ Mode of ventilation at initiation of ventilation } & Pressure cycle mode $=13$ & $\mathrm{BPAP}=55$ & \\
\hline & Volume cycle mode $=12$ & $\mathrm{CPAP}=16$ & \\
\hline \multicolumn{4}{|l|}{ Duration of ventilator use per day at time of initiation, $n(\%)$} \\
\hline Nocturnal & $0(0)$ & $59(83)$ & $<.001$ \\
\hline Extended daytime & $0(0)$ & $8(11)$ & .11 \\
\hline Whole day & $25(100)$ & $4(6)$ & $<.001$ \\
\hline \multicolumn{4}{|l|}{ Comorbidities, $n(\%)$} \\
\hline Impaired mobility & $21(84)$ & $47(66)$ & .13 \\
\hline Gastrostomy or nasogastric tube feeding & $18(72)$ & $28(39)$ & .006 \\
\hline Intellectual impairment & $18(72)$ & $27(38)$ & .005 \\
\hline Location of care: residing at home or in community, $n(\%)$ & $13(52)$ & $71(100)$ & $<.001$ \\
\hline \multicolumn{4}{|l|}{ Highest education level achieved or attending at time of report, $n$} \\
\hline Pre-school training centre & 4 & 7 & \\
\hline Hospital school & 2 & 0 & \\
\hline Primary school & 5 & 14 & \\
\hline Secondary school & 8 & 29 & \\
\hline University & 1 & 9 & \\
\hline No schooling & 5 & 12 & \\
\hline
\end{tabular}

incidence of subjects initiated on long-term mechanical ventilation and the cumulative prevalence of subjects during the study period, respectively. Of note, we did not receive new referrals in 2003 due to the severe acute respiratory syndrome epidemic. The demographic characteristics are listed in Table 1. There was a male predominance in both the invasive mechanical ventilation and NIV groups, with a total of 72 male and 24 female subjects. Twentyfive of the subjects $(26 \%)$ required invasive mechanical ventilation, of whom 13 were put on pressure-type ventilators and the rest on volume-type ventilators. All subjects, except one, were using non-cuffed types of tracheostomy tubes. Eight subjects used speaking valves to facilitate their speech. Seventy-one subjects (74\%) required NIV, with 55 receiving bi-level positive airway pressure and 16 receiving CPAP. All subjects receiving invasive mechanical ventilation required whole-day ventilatory support initially, whereas the majority of subjects receiving NIV (83\%) required nocturnal support only $(P<.001)$. In addition, subjects were started on invasive mechanical ventilation at a much younger age than subjects receiving NIV (median age of $1.6 \mathrm{y}$ old vs $11.2 \mathrm{y}$ old, $P=.003$ ). At the time of the report, 12 of the subjects receiving NIV never attended any schooling because either they were too young or they died before school age. Four subjects receiving invasive mechanical ventilation were waiting for placement in pre- school training centers. Another school age subject receiving invasive mechanical ventilation was discharged back to his home in China. The remaining subjects in both groups had attained or were attending different levels of education in mainstream or special schools, as shown in Table 1 . The condition of 2 hospitalized subjects receiving invasive mechanical ventilation prevented them from going to special schools; hence, education was provided by hospital schools. There were a greater proportion of subjects receiving NIV than subjects receiving invasive mechanical ventilation who could attain university degrees.

Table 2 shows the underlying medical conditions accounting for the long-term mechanical ventilation. Fortyeight of the subjects (50\%) suffered from various types of neuromuscular diseases: 24 (25\%) had abnormal ventilatory control related to neurological, metabolic, or genetic conditions; 17 (18\%) had airway problems; $6(6 \%)$ had chronic lung diseases; and the remaining one had restrictive chest wall deformity. The most common indication was abnormal ventilatory control in subjects receiving invasive mechanical ventilation (52\%; 13 of 25 subjects) and neuromuscular disease in subjects receiving bi-level positive airway pressure (73\%; 40 of 55 subjects). Among the 16 subjects receiving CPAP, 11 had airway-related problems and 5 had mixed obstructive and central ele- 


\section{Long-Term Management for Ventilator-Assisted Children}

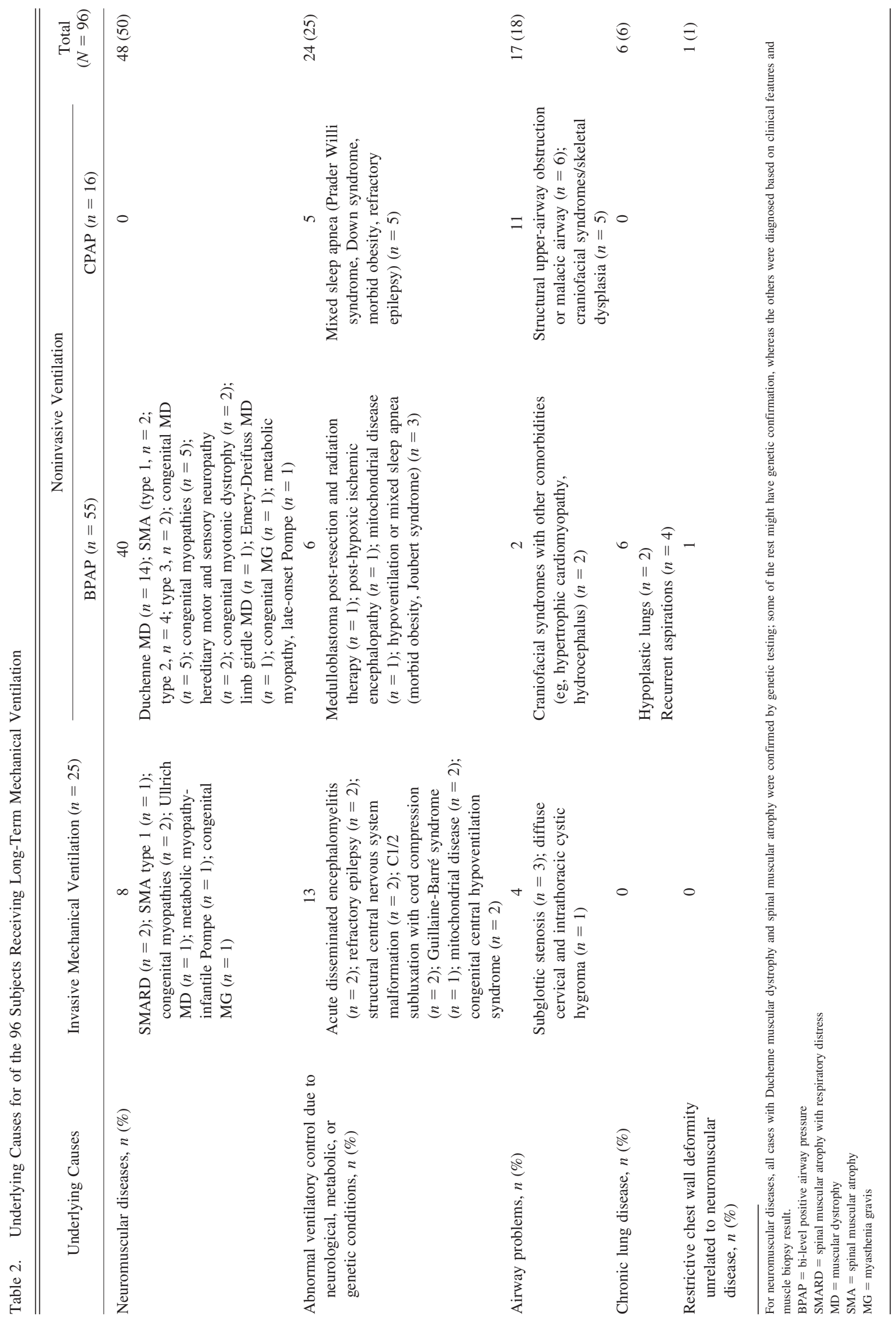




\section{Long-Term Management for Ventilator-Assisted Children}

Table 3. Reasons Subjects Receiving Invasive Ventilation Could Not Be Discharged Home

\begin{tabular}{ll}
\hline \hline \multicolumn{1}{c}{ Reasons } & $n$ \\
\hline Parental stress, parental health problems & 5 \\
Parental non-acceptance for home care & 3 \\
Parental non-acceptance and family lived & 2 \\
$\quad$ outside Hong Kong & 2 \\
Parental non-acceptance and child was signed & \\
$\quad$ off for adoption & \\
\hline$n=12$. & \\
\hline
\end{tabular}

Table 4. The Hospital Course From Acute Hospital to Final Home Discharge of the 13 Subjects Receiving Invasive Ventilation

\begin{tabular}{lcc}
\hline \hline \multicolumn{1}{c}{ Variables } & Mean \pm SD & $\begin{array}{c}\text { Median } \\
\text { (Interquartile Range) }\end{array}$ \\
\hline $\begin{array}{l}\text { Length of stay in referring acute } \\
\text { care hospital, d }\end{array}$ & $440.5 \pm 520.4$ & $367(143-507)$ \\
$\begin{array}{l}\text { Length of stay in rehabilitation } \\
\text { hospital (Duchess of Kent }\end{array}$ & $98.8 \pm 87.5$ & $71(42-114)$ \\
$\quad$ Children's Hospital), d & & \\
$\begin{array}{l}\text { Total No. of days from date of } \\
\text { tracheostomy to home } \\
\text { discharge, d }\end{array}$ & $480 \pm 501.3$ & $350(207-545)$ \\
\hline
\end{tabular}

ments of sleep apnea related to underlying syndromes or neurological conditions.

Concerning comorbidities, a large number of our subjects had impaired mobility $(71 \%, 68$ of 96 subjects) and were wheelchair users. For those who required extended ventilatory support in daytime, the ventilator could be mounted to the wheelchair by the use of a bag or a ventilator tray. In addition, $48 \%$ (46 of 96) of the subjects had oromotor dysfunction requiring assisted non-oral feeding, and $47 \%$ (45 of 96) of the subjects had intellectual impairment. Most of the subjects (87.5\%) in our cohort resided at home or in the community, including 13 subjects receiving invasive mechanical ventilation and all of the subjects receiving NIV ( $52 \%$ vs $100 \%, P<.001)$. Twelve subjects could not be discharged home due to social reasons, as shown in Table 3. Parental non-acceptance and parental stress were the major reasons for them to remain in the hospital. Children receiving invasive mechanical ventilation are considered to be the most complicated type of patients to be discharged; hence, lengthy hospital stays often result. In our cohort, the median length of stay of these 13 subjects was $367 \mathrm{~d}$ (IQR 143-507 d) in the acute referring hospitals and $71 \mathrm{~d}$ (IQR 42-114 d) in our hospital before final home discharge (Table 4).

Table 5 shows the outcomes of 96 subjects. One subject with Guillain-Barré syndrome gradually improved. She
Table 5. Outcomes of Subjects Receiving Long-Term Mechanical Ventilation

\begin{tabular}{lccc}
\hline \hline \multicolumn{1}{c}{ Outcomes } & $\begin{array}{c}\text { Invasive } \\
\text { Mechanical } \\
\text { Ventilation } \\
(n=25)\end{array}$ & $\begin{array}{c}\text { Noninvasive } \\
\text { Ventilation } \\
(n=71)\end{array}$ & $P$ \\
\hline $\begin{array}{l}\text { Weaned off of ventilator, } n \\
\text { Lost to follow-up due to } \\
\text { transition to adult units } \\
\text { or referred to other } \\
\text { pediatric departments, } n\end{array}$ & 1 & 7 & .68 \\
\begin{tabular}{l} 
Death, $n$ \\
\hline
\end{tabular} & 0 & 7 & .19 \\
\end{tabular}

was successfully taken off of the ventilator and decannulated. Among the subjects receiving NIV, 7 subjects could be weaned off of mechanical ventilation due to improvement of their underlying airway problems or chronic lung diseases. The overall successful weaning rate was $8 \%$ ( 8 of 96 subjects). Nineteen subjects initially receiving nocturnal bi-level positive airway pressure had disease progression and required extension of NIV in the daytime. Eight of these subjects received bi-level positive airway pressure via a mouthpiece in the daytime, and the other subjects used a nasal mask or nasal prongs as the interface, depending on their ability to provide a tight seal around a mouthpiece, the need to wear eyeglasses, or their personal preferences. Five of these subjects required home mechanical insufflator-exsufflators in addition to the standard airway clearance techniques. Seven subjects receiving NIV either received transitional care to adult units or were referred to other pediatric departments because of geographical reason. These 7 subjects had been managed in our hospital for a median duration of 33 months.

All subjects receiving invasive mechanical ventilation were still alive at the time of the report. The subject with the longest survival in our cohort has been receiving invasive mechanical ventilation for $>18 \mathrm{y}$. He suffered from acute disseminated encephalomyelitis with high cervical cord involvement. Seventeen subjects receiving NIV passed away, of whom 15 suffered from progressive neuromuscular diseases (Table 6). The median age of death was 25.0 y (IQR 8.7-26.5). Nine died from unrelenting respiratory failure or severe chest infection, 2 died of progressive heart failure, and 6 had sudden unwitnessed arrest with uncertain cause of death. Among these 17 subjects, do-not-resuscitate orders were in place in $8 ; 3$ of the subjects had advance directives, whereas the other 5 subjects' family members made the decision of no resuscitation at the terminal events.

\section{Discussion}

To our knowledge, this is the first pediatric long-term mechanical ventilation cohort in Hong Kong and also one 


\section{Long-Term Management for Ventilator-Assisted Children}

Table 6. Causes of Death in 17 Subjects Receiving Noninvasive Ventilation

\begin{tabular}{|c|c|c|c|c|}
\hline Subject & Underlying Diagnosis & $\begin{array}{l}\text { Type of } \\
\text { Ventilation }\end{array}$ & Causes of Death & DNR Order \\
\hline 1 & Duchenne MD & BPAP & Sudden arrest & No \\
\hline 2 & Congenital MD & BPAP & Sudden arrest & Decided at terminal event \\
\hline 3 & Restrictive chest wall deformity & BPAP & Sudden arrest & No \\
\hline 4 & Duchenne MD & BPAP & Uncontrolled heart failure & Decided at terminal event \\
\hline 5 & Duchenne MD & BPAP & Uncontrolled heart failure & Decided at terminal event \\
\hline 6 & Congenital myopathy & BPAP & Respiratory failure + pneumonia & No \\
\hline 7 & Duchenne MD & BPAP & Respiratory failure + pneumonia & Decided at terminal event \\
\hline 8 & HSMN 1 & BPAP & Sudden arrest & No \\
\hline 9 & SMA type 1 & BPAP & Respiratory failure & Yes \\
\hline 10 & Duchenne MD & BPAP & Respiratory failure & Yes \\
\hline 11 & Duchenne MD & BPAP & Sudden arrest & Decided at terminal event \\
\hline 12 & Duchenne MD & BPAP & Respiratory failure & No \\
\hline 13 & Duchenne MD & BPAP & Respiratory failure + pneumonia & No \\
\hline 14 & Duchenne MD & BPAP & Respiratory failure + pneumonia & No \\
\hline 15 & SMA type 1 & BPAP & Respiratory failure & Yes \\
\hline 16 & $\begin{array}{l}\text { Craniofacial syndrome with } \\
\text { hypertrophic cardiomyopathy }\end{array}$ & BPAP & Sudden arrest & No \\
\hline 17 & Duchenne MD & BPAP & Respiratory failure + pneumonia & No \\
\hline $\begin{array}{l}\mathrm{DNR}=\text { do- } \\
\text { MD }=\text { mus } \\
\text { BPAP }=\text { bi } \\
\text { HSMN }=\text { h } \\
\text { SMA }=\text { spi }\end{array}$ & $\begin{array}{l}\text { itate } \\
\text { ophy } \\
\text { tive airway pressure } \\
\text { notor and sensory neuropathy } \\
\text { lar atrophy }\end{array}$ & & & \\
\hline
\end{tabular}

of the largest longitudinal reviews for these children in Asia. There are several important findings in our study. First, there has been an increasing prevalence of subjects receiving long-term mechanical ventilation over the past 2 decades, from 2 at the commencement of the program to 96 at the time of the report. The increasing trend in ventilationassisted children has been observed worldwide. ${ }^{9,14,17,18,21,25}$ The advancement in medical care in children with critical illnesses and increased family acceptance for home care for these children are important contributing factors. Another major factor is the improvement and wider availability of pediatric home ventilators, especially the noninvasive type, as supported by the increasing use of NIV over invasive mechanical ventilation over these years. In our cohort, $26 \%$ of subjects were put on invasive mechanical ventilation; this percentage was comparable with the United Kingdom (22\%), ${ }^{21}$ Switzerland (31\%), ${ }^{26}$ and Turkey $(32 \%)^{27}$; higher than Auckland $(3 \%)^{14}$ and Canada $(17 \%)^{9}$; and lower than Italy (41\%), ${ }^{19}$ Massachusetts (49\%), ${ }^{18}$ and the Netherlands $(51 \%) .{ }^{25}$ Whereas this could be due to the differences in study period, inclusion criteria, or disease prevalence, it could also be due to the variation of clinical practice in initiation of long-term mechanical ventilation in different types of diseases, socio-cultural factors, or difference in health-care systems across different countries. For example, the use of invasive mechanical ventilation in children with severe neurological conditions with minimal conscious state or neuromuscular disease like spinal muscular atrophy type 1 remains controversial across different regions. The health-care financing system, in particular, may affect physicians or parents' readiness to proceed with tracheostomy and home invasive mechanical ventilation. In other countries, socio-cultural and family acceptance factors may lead to the wider use of NIV. In Hong Kong, Chinese parents do not readily accept redirection of care because pediatric palliative care for nononcological illness is still underdeveloped. Therefore, they do not have great resistance for their children to proceed with tracheostomy and ventilation for the purpose of prolonging life, although they may not have a plan for discharge or have the necessary motivation, optimism, and psychosocial resources to provide home care for their children. ${ }^{28}$ This is reflected in the findings that parental stress and non-acceptance are the major reasons for subjects receiving invasive mechanical ventilation not being discharged home when they are medically stable.

The second important finding was an observed male preponderance of $75 \%$ in our cohort, higher than the reported prevalence of slightly above $50 \%$ in previous studies conducted in Italy ${ }^{19}$ and Canada. ${ }^{9}$ This may be partly explained by the high proportion of subjects with X-linked neuromuscular diseases: 14 with Duchenne muscular dystrophy, one with Emery-Dreifuss muscular dystrophy, and one with congenital myopathy. Even after excluding 


\section{Long-Term Management for Ventilator-Assisted Children}

these 16 subjects, the male predominance persisted, with a male/female ratio of 56:24. In addition, it is noteworthy that airway and lung problems were relatively less common conditions accounting for long-term mechanical ventilation in our cohort as compared with other western studies. ${ }^{9,10,13,16,21}$ Our finding indirectly reflects the difference in prevalence of chronic diseases in western and Asian countries (eg, the much lower prevalence of cystic fibrosis in the Asian population).

There have been a substantial number of studies and guidelines to support NIV in reducing morbidity and mortality and improving quality of life in patients with neuromuscular diseases. ${ }^{29,30}$ With advanced NIV technology, home care of even young children with milder forms of neuromuscular diseases, like certain congenital myopathies and milder types of spinal muscular atrophy, can be facilitated. In our cohort, 26 of the 71 subjects (37\%) initiated NIV before the age of $6 \mathrm{y}$, whereas only 8 of 57 children with childhood-onset hereditary neuromuscular diseases could be maintained on home NIV in a recent Korean study. ${ }^{24}$ However, nearly half of these Korean subjects received invasive mechanical ventilation directly without a trial of NIV. In addition, their study excluded patients suffering from Duchenne muscular dystrophy. In another review conducted in Taiwan, NIV was also infrequently adopted in only 3 of the 102 children receiving long-term mechanical ventilation. ${ }^{23}$

Another notable finding was the high prevalence of comorbidities in subjects receiving invasive mechanical ventilation in our cohort. Although there was no significant difference in limitation in mobility between subjects receiving invasive mechanical ventilation and those receiving NIV ( $84 \%$ vs $66 \%, P=.13$ ), there were significantly more subjects in the former group who required gastrostomy or nasogastric tube feeding ( $72 \%$ vs $39 \%, P=.006$ ) and had intellectual impairment (72\% vs 38\%, $P=.005$ ). This suggests the complex care for subjects receiving invasive mechanical ventilation and therefore additional challenges when planning for home care. Similarly, subjects receiving invasive mechanical ventilation encounter greater difficulties in re-integrating into the school system than subjects receiving NIV. In Hong Kong, there is a liaison system between the Education Department Bureau and the Hospital Authority for placement of these medically complex children in special schools or, should assistance be required, when these children are attending mainstream schools. Our ventilator care program also organizes regular training courses for school nurses and teaching assistants that will take care of these children. However, there were still subjects receiving invasive mechanical ventilation for whom special schools decided that they could not cope with the complexity of care, and these children could only receive education via hospital school.
The clinical practice of step-down care varies from institution to institution. In a recent Canadian cohort of 35 children receiving invasive mechanical ventilation in an acute care hospital, ${ }^{8} 15$ could be discharged home directly, 2 died, and the remaining 18 were transferred to a rehabilitation hospital similar to our setting. The length of stay at the acute care hospital for the whole cohort was $125 \mathrm{~d}$ (IQR 72.5-195 d). For the 12 of the 18 children who were discharged home, the median length of stay from acute care hospital admission to discharge from the rehabilitation hospital was $240 \mathrm{~d}$ (IQR 93.5-419.5 d). Compared with this Canadian study, our 13 children receiving invasive mechanical ventilation had stayed much longer in the acute referring hospital, whereas they spent a shorter period of time at our hospital. The finding suggests the local need for earlier referral from the acute care setting to our hospital so that these children can receive earlier rehabilitation and the caregivers can be empowered to take care of them at an earlier stage. In terms of health-care utilization, this will also reduce pediatric ICU bed occupancy and overall medical cost because the cost per patient day in a chronic care facility like our setting is $\sim 4,600 \mathrm{HK}$ dollar (590 United States dollars), whereas the cost per patient day in a pediatric ICU bed is tripled $(13,641 \mathrm{HK}$ dollars [1,749 United States dollars]). ${ }^{31}$ To tackle this problem of inter-hospital referral, the implementation of a standardized discharge process and designation of a discharge coordinator may help to streamline the care of these medically complex children and hasten their discharge process. ${ }^{32}$

Our study also showed that many of these children receiving long-term mechanical ventilation could be discharged home after adequate and proper training of caregivers and securing financial support for the families. Upon discharge, families would be responsible for most of the home care costs, including equipment, disposable medical supplies, medications, and transport. From our experience, the rental costs related to equipment and consumables usually range from 2,200 to 4,000 HK dollars (282-513 United States dollars)/month, depending on the child's medical complexity. For instance, it is more expensive to look after children receiving invasive mechanical ventilation at home because the portable home ventilator designated for invasive ventilation is more expensive than the NIV ventilator. Also, these children usually have more associated comorbidities, and more medical consumables may be required. Unlike in countries with insurance coverage for home care or direct funding of the home caregivers by a social services department, 7,33,34 the financial burden on families can be much higher for their children to be cared for at home than for them to remain in a public hospital in Hong Kong because the hospital bed fees are heavily funded by the government. Families with very low household income can apply for the comprehensive social security assistance 


\section{Long-Term Management for Ventilator-Assisted Children}

scheme, and then all of the rental of medical equipment and consumables would be covered. For middle-income families, their children are eligible for a fixed disability allowance of 3,160 HK dollar (405 United States dollars)/month. This sum of money may cover most of the rental fees for medical items. However, due to the lack of in-home nursing provision in Hong Kong, one of the parents may need to quit his or her job to look after their child or employ a home helper to assist in child care. This will impose an indirect cost on the family. Parents also need to prepare for significant lifestyle adjustment, with an increase in physical and emotional demand and loss of personal time, to provide home care for their children receiving long-term mechanical ventilation. Furthermore, because Hong Kong is one of the most densely populated cities in the world, with a much lower living area per capita, home modification or rehousing may be required to accommodate the children and the medical equipment at home.

Despite all these non-medical factors that are potential barriers to discharge, ${ }^{35}$ more than half of our subjects receiving invasive mechanical ventilation and all of the subjects receiving NIV could be discharged home. This was in contrast to a study in Taiwan, ${ }^{23}$ where home care was only possible for $15.1 \%$ of 102 ventilator-assisted children. When the medical team considers the initiation of longterm mechanical ventilation in children, a thorough discussion with the family about the pros and cons of invasive versus noninvasive ventilation should be conducted. The burden on the family to provide home care for these children should not be underestimated. Otherwise, these children may end up with unduly long hospitalization. Irrespective of the choice of NIV versus invasive mechanical ventilation, a comprehensive transdisciplinary program that supports the training of caregivers; coordinates the discharge process; provides long-term follow up; and liaises with various government departments, including education, housing, transport, and social service departments, and medical equipment companies is mandatory to the success of home care for children receiving long-term mechanical ventilation. ${ }^{7,32}$

Last, there was a striking difference between the outcomes of subjects receiving invasive mechanical ventilation and those receiving NIV in our cohort. The overall mortality rate was $17.7 \%$, as compared with $15 \%$ in a Canadian study with similar duration of follow-up. ${ }^{9}$ All mortalities (17 subjects) in our study occurred in subjects receiving NIV $(P=.005)$; in contrast, there was $11 \%$ mortality in children receiving NIV and $30 \%$ mortality for children receiving invasive mechanical ventilation in the Canadian cohort. The $100 \%$ survival rate of subjects receiving invasive mechanical ventilation in our cohort indicates that home care by trained parents and lay caregivers can be safe and efficient. ${ }^{36}$ Fifteen of the 17 subjects who died in our cohort suffered from progressive neuro-

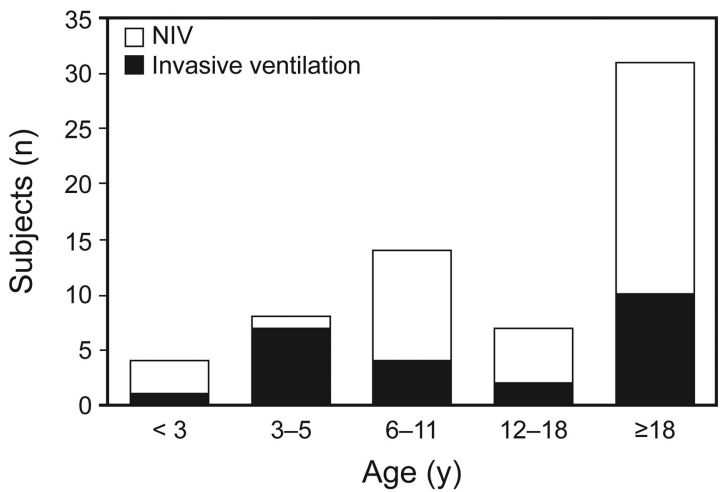

Fig. 3. Age distribution of subjects receiving long-term mechanical ventilation at the time of the study. NIV = noninvasive ventilation.

muscular diseases. The median age of death was $25.0 \mathrm{y}$ old. At the time of death, they were ventilated for a median duration of 5.9 y (IQR 2.1-7.5). This was comparable with the finding of an increase in survival by $5-6$ y after initiating NIV in subjects with Duchenne muscular dystrophy in the literature. ${ }^{37}$ However, because subjects may deteriorate or go into a sudden cardio-respiratory arrest, advance directives and do-not-resuscitate orders should ideally be discussed with them and their families in advance, and the discussions should be documented clearly in their medical records for emergency situations. Overall, the rate of successful weaning in our cohort was relatively low (8\%) as compared with the Auckland group, ${ }^{14}$ probably related to the fact that most of the subjects had irreversible underlying conditions (eg, neuromuscular diseases or permanent neurological insults). At the time of the report, about one third of our subjects have reached adult age (Fig. 3). Although adult respiratory units are more ready to accept subjects receiving NIV, a specialized center for adult subjects receiving invasive mechanical ventilation has yet to be developed in Hong Kong. A transitional program for our subjects receiving invasive mechanical ventilation to adult units is advisable in our local setting in view of the increasing number and survival of these subjects.

We need to address our study limitations. First, our study could not include all of the children receiving longterm mechanical ventilation in Hong Kong because a few of the children were discharged home directly from acute care hospitals, a few were still staying in ICUs in other hospitals, and a few were receiving in-patient care in the other designated rehabilitation center. We may have underestimated the incidence and prevalence of children started on long-term mechanical ventilation. Nevertheless, we believe our findings should give a good reflection of the local scene because we look after nearly two thirds of in-patient rehabilitation service for these children in the territory. Second, we did not evaluate the psychological stress and burden on the immediate caregivers and the families due to the retrospective nature of the study. Fi- 


\section{Long-Term Management for Ventilator-Assisted Children}

nally, we were unable to accurately analyze the overall health-care utilization of this group of children living in the community, because $>70 \%$ of the primary care is provided in the private sector and the creation of an electronic database linking the public and private sectors is under way in Hong Kong.

\section{Conclusions}

Our local study showed an increasing prevalence of children receiving long-term mechanical ventilation, comparable with that of western countries. However, there were distinct demographic characteristics, underlying diseases, co-morbidities, and outcomes of our cohort. Home care is feasible in the majority of these children in Hong Kong despite the lack of in-home nursing provision. The findings from our study will be important for our local health-care planning, and the success of our ventilator care program may provide useful information to nearby Asian cities or countries.

\section{ACKNOWLEDGMENT}

We thank Ivy Ip, Sam Wong, and Wilfred Wong for providing statistical analysis for the study and our colleagues for help in running the ventilator care program. We are also grateful to the families of our subjects for their unfailing love for their children and for providing encouragement and support to our program. We also thank the unfailing support of the Society for the Relief of Disabled Children.

\section{REFERENCES}

1. Finder JD, Birnkrant D, Carl J, Farber HJ, Gozal D, Iannaccone ST, et al. Respiratory care of the patient with Duchenne muscular dystrophy: ATS consensus statement. Am J Respir Crit Care Med 2004; 170(4):456-465.

2. Lemoine TJ, Swoboda KJ, Bratton SL, Holubkov R, Mundorff M, Srivastava R. Spinal muscular atrophy type 1: are proactive respiratory interventions associated with longer survival? Pediatr Crit Care Med 2012;13(3):e161-e165.

3. Murphy J. Medically stable children in PICU: better at home. Paediatr Nurs 2008;20(1):14-16.

4. Simonds AK. Recent advances in respiratory care for neuromuscular disease. Chest 2006;130(6):1879-1886.

5. Nørregaard O. Noninvasive ventilation in children. Eur Respir J 2002;20(5):1332-1342.

6. Panitch HB, Downes JJ, Kennedy JS, Kolb SM, Parra MM, Peacock J, Thompson MC. Guidelines for home care of children with chronic respiratory insufficiency. Pediatr Pulmonol 1996;21(1): $52-56$.

7. Jardine $\mathrm{E}, \mathrm{Wallis} \mathrm{C}$. Core guidelines for the discharge home of the child on long-term assisted ventilation in the United Kingdom: UK Working Party on Paediatric Long Term Ventilation. Thorax 1998; 53(9):762-767.

8. Amin R, Sayal A, Syed F, Daniels C, Hoffman A, Moraes TJ, Cox P. How long does it take to initiate a child on long-term invasive ventilation? Results from a Canadian pediatric home ventilation program. Can Respir J 2015;22(2):103-108.
9. Amin R, Sayal P, Syed F, Chaves A, Moraes TJ, MacLusky I. Pediatric long-term home mechanical ventilation: twenty years of follow-up from one Canadian center. Pediatr Pulmonol 2014;49(8): 816-824.

10. Appierto L, Cori M, Bianchi R, Onofri A, Catena S, Ferrari M, Villani A. Home care for chronic respiratory failure in children: 15 years experience. Paediatr Anaesth 2002;12(4):345-350.

11. Bertrand P, Fehlmann E, Lizama M, Holmgren N, Silva M, Sánchez I. Home ventilatory assistance in Chilean children: 12 years' experience. Arch Bronconeumol 2006;42(4):165-170.

12. Chatwin M, Tan HL, Bush A, Rosenthal M, Simonds AK. Long term non-invasive ventilation in children: impact on survival and transition to adult care. PLoS One 2015;10(5):e0125839.

13. Com G, Kuo DZ, Bauer ML, Lenker CV, Melguizo-Castro MM, Nick TG, et al. Outcomes of children treated with tracheostomy and positive-pressure ventilation at home. Clin Pediatr 2013;52(1): 54-61.

14. Edwards EA, Hsiao K, Nixon GM. Paediatric home ventilatory support: the Auckland experience. J Paediatr Child Health 2005;41(12): 652-658.

15. Edwards EA, Nixon GM, Australasian Paediatric Respiratory Group Working Party on Home Ventilation. Paediatric home ventilatory support: changing milieu, proactive solutions. J Paediatr Child Health 2013;49(1):13-18.

16. Fauroux B, Boffa C, Desguerre I, Estournet B, Trang H. Long-term noninvasive mechanical ventilation for children at home: a national survey. Pediatr Pulmonol 2003;35(2):119-125.

17. Goodwin S, Smith H, Langton Hewer S, Fleming P, Henderson AJ, Hilliard T, Fraser J. Increasing prevalence of domiciliary ventilation: changes in service demand and provision in the South West of the UK. Eur J Pediatr 2011;170(9):1187-1192.

18. Graham RJ, Fleegler EW, Robinson WM. Chronic ventilator need in the community: a 2005 pediatric census of Massachusetts. Pediatrics 2007;119(6):e1280-e1287.

19. Racca F, Berta G, Sequi M, Bignamini E, Capello E, Cutrera R, et al. Long-term home ventilation of children in Italy: a national survey. Pediatr Pulmonol 2011;46(6):566-572.

20. Rose L, McKim DA, Katz SL, Leasa D, Nonoyama M, Pedersen C, et al. Home mechanical ventilation in Canada: a national survey. Respir Care 2015;60(5):695-704.

21. Wallis C, Paton JY, Beaton S, Jardine E. Children on long-term ventilatory support: 10 years of progress. Arch Dis Child 2011; 96(11):998-1002.

22. Sakakihara Y, Yamanaka T, Kajii M, Kamoshita S. Long-term ventilator-assisted children in Japan: a national survey. Acta Paediatr Jpn 1996;38(2):137-142.

23. Hsia SH, Lin JJ, Huang IA, Wu CT. Outcome of long-term mechanical ventilation support in children. Pediatr Neonatol 2012;53(5): 304-308.

24. Han YJ, Park JD, Lee B, Choi YH, Suh DI, Lim BC, Chae JH. Home mechanical ventilation in childhood-onset hereditary neuromuscular diseases: 13 years' experience at a single center in Korea. PLoS One 2015;10(3):e0122346.

25. Paulides FM, Plötz FB, Verweij-van den Oudenrijn LP, van Gestel JP, Kampelmacher MJ. Thirty years of home mechanical ventilation in children: escalating need for pediatric intensive care beds. Intensive Care Med 2012;38(5):847-852.

26. Kamm M, Burger R, Rimensberger P, Knoblauch A, Hammer J. Survey of children supported by long-term mechanical ventilation in Switzerland. Swiss Med Wkly 2001;131(19):261-266.

27. Oktem S, Ersu R, Uyan ZS, Cakir E, Karakoc F, Karadag B, et al. Home ventilation for children with chronic respiratory failure in Istanbul. Respiration 2008;76(1):76-81. 


\section{Long-Term Management for Ventilator-Assisted Children}

28. Glass C, Grap MJ, Battle G. Preparing the patient and family for home mechanical ventilation. Medsurg Nurs 1999;8(2):99-101, 104-107.

29. Birnkrant DJ, Bushby KM, Amin RS, Bach JR, Benditt JO, Eagle M, et al. The respiratory management of patients with duchenne muscular dystrophy: a DMD care considerations working group specialty article. Pediatr Pulmonol 2010;45(8):739-748.

30. Schroth MK. Special considerations in the respiratory management of spinal muscular atrophy. Pediatrics 2009;123:S245-S249.

31. Hospital Authority. Annual Report 2014-2015. http://www.ha.org. hk/upload/publication_13/500.pdf. Accessed June 28, 2015.

32. Tearl DK, Cox TJ, Hertzog JH. Hospital discharge of respiratorytechnology-dependent children: role of a dedicated respiratory care discharge coordinator. Respir Care 2006;51(7):744-749.

33. Dybwik K, Tollåli T, Nielsen EW, Brinchmann BS. "Fighting the system": families caring for ventilator-dependent children and adults with complex health care needs at home. BMC Health Serv Res 2011;11: 156.

34. Elias ER, Murphy NA. Home care of children and youth with complex health care needs and technology dependencies. Pediatrics 2012; 129(5):996-1005.

35. Graf JM, Montagnino BA, Hueckel R, McPherson ML. Children with new tracheostomies: planning for family education and common impediments to discharge. Pediatr Pulmonol 2008;43(8):788-794.

36. Tibballs J, Henning R, Robertson CF, Massie J, Hochmann M, Carter B, et al. A home respiratory support programme for children by parents and layperson carers. J Paediatr Child Health 2010;46(1):57-62.

37. Simonds AK, Muntoni F, Heather S, Fielding S. Impact of nasal ventilation on survival in hypercapnic Duchenne muscular dystrophy. Thorax 1998;53(11):949-952. 